\title{
Klebsiella capsular type versus site of isolation
}

\author{
EVE RISER,* PAUL NOONE $\dagger$
}

From the * Department of Pediatrics, Arizona Medical Center, Tucson, The University of Arizona, Arizona 85724, USA and †The Royal Free Hospital, Pond Street, Hampstead, London NW3 2QG

SUMMARY More than 1750 clinical isolates of klebsiella were collected over a period of six years $\vec{\sigma}$ from two different hospitals and capsular typed by the fluorescent antibody technique. A correlation was made between type and site of isolation. Many types were found to be associated more frequently with one site, which suggested a predilection of some capsular types for certain sites of infection. The ${ }_{i}^{+}$ site may also be a factor contributing to the virulence of a particular type. A greater antibioticis resistance was often noted in types isolated from their predominant sites; however, antibiograms $N$ were not consistent for a type from a given site. The combination of site specificity, resistance, and윽 another 'virulence factor' may all be involved in the determination of a pathogenic strain.

Several workers have proposed that particular capsular types of klebsiella might favour certain sites of isolation. ${ }^{1-4}$ But Ørskov ${ }^{5}$ suggested that some of these associations were probably due to cross infection, and Casewell ${ }^{6}$ attributed some to endemic infection because of the high numbers involved. Casewell states that there is no evidence at present that a serotype can be associated with a source, except types 1 to 6 . However, Ørskov ${ }^{7}$ found that type 47 was the most common serotype from the sputum of inpatients from about 50 different hospitals in Denmark. This type constituted $6.9 \%$ of 89 klebsiella strains isolated from sputum.

Klebsiellae identified from two different hospital studies in London were therefore examined to see if there was any evidence of a relationship between type and site.

\section{Material and methods}

Klebsiellae from routine specimens and two epidemiological studies at the Middlesex Hospital ${ }^{8}$ and the Royal Free Hospital ${ }^{9}$ were typed by the new fluorescent antibody technique. ${ }^{10}$ The capsular types were then correlated with the site of isolation in the patients.

\section{Results}

Among the 1750 unknowns identified some types were isolated more frequently from particular sites. Table 1 lists these capsular types with the number and percentage of each from their most common

Accepted for publication 9 October 1980 sources. The majority of the klebsiellae were isolated $\overrightarrow{ }$ from sputum $(21 \cdot 7 \%)$ or urine $(29 \%)$. Table 2 contains $\infty$ the types recovered predominantly from urine, sputum, wounds, and stools.

\section{Discussion}

The specimens for this study were collected between $\stackrel{\mathcal{D}}{\circ}$ 1971 and 1974 from the Middlesex Hospital and $\vec{\circ}$ between 1974 and 1977 from the Royal Free Hospital 3 in London.

Most of the specimens yielding a particular type? were taken from patients in different wards in these two hospitals; however, all isolations of a given type were considered for the analysis. This included the 3 . multiple isolations of a type from one ward which, when it did occur, was generally confined to two or three patients. The appearance within a short period of time of the same type in more than one patient in? a ward suggests transmission, but because of the limited extent of spreading, such a strain could not be considered endemic or the occurrence an epidemic. N These recurrent types could be isolated from variousin sites among the different patients or from several sites in the same patient. Multiple isolations of a type from $\omega$ one ward did not necessarily imply that proximity would determine subsequent sites of infection. Other? factors would have to be considered, such as the nature of the ward and the techniques of patient care ${ }^{-}$ Nevertheless strains involved in known outbreaks were not included in the tables, although assessmento of the type/site relationship during an epidemic was? still of interest. Otherwise it was decided to include multiple isolations of a type from one ward and froms all sites of a single patient. Such samplings were 552 
Table 1 Klebsiella capsular types from laboratory specimens and their most common site of isolation

\begin{tabular}{|c|c|c|c|c|c|c|c|}
\hline \multirow{2}{*}{$\begin{array}{l}\text { Capsular type } \\
1\end{array}$} & \multirow{2}{*}{$\begin{array}{l}\begin{array}{l}\text { Number of specimens with site } \\
\text { indicated }\end{array} \\
5\end{array}$} & \multirow{2}{*}{$\begin{array}{l}\text { Site } \\
\text { sputum }\end{array}$} & \multicolumn{2}{|c|}{ Number of specimens } & \multirow[t]{2}{*}{ Site } & \multicolumn{2}{|c|}{ Number of specimens } \\
\hline & & & 3 & $(60)$ & & & \\
\hline 2 & 24 & urine & 13 & $(54 \cdot 2)$ & sputum & 4 & $(16 \cdot 7)$ \\
\hline 3 & 13 & sputum & 5 & $(38.5)$ & & & \\
\hline 4 & 5 & sputum & 4 & (80) & & & \\
\hline 9 & 12 & urine & 9 & (75) & & & \\
\hline 10 or $61^{*}$ & 8 & urine & 5 & $(62 \cdot 5)$ & & & \\
\hline 11 & 11 & urine & 5 & $(45 \cdot 5)$ & & & \\
\hline 12 & 7 & sputum & 4 & (57) & & & \\
\hline 14 & 16 & stool & 5 & $(31 \cdot 3)$ & sputum & 5 & $(31 \cdot 3)$ \\
\hline 15 & 2 & urine & 2 & $(100)$ & & & \\
\hline 17 & 18 & urine & 6 & $(33 \cdot 3)$ & & & \\
\hline 18 & 16 & urine & 4 & (25) & & & \\
\hline 19 & 16 & urine & 5 & $(31 \cdot 3)$ & & & \\
\hline 21 & 41 & urine & 16 & (39) & sputum & 5 & $(12 \cdot 2)$ \\
\hline 23 & 5 & sputum & 3 & (60) & & & \\
\hline 24 & 15 & urine & 9 & (60) & & & \\
\hline 25 & 16 & sputum & 13 & $(81 \cdot 3)$ & & & \\
\hline 27 & 15 & urine & 9 & (60) & sputum & 6 & (40) \\
\hline 29 & 6 & urine & 3 & (50) & & & \\
\hline 30 & 16 & wound & 7 & $(43 \cdot 8)$ & urine & 4 & (25) \\
\hline 31 & 20 & wound & 7 & (35) & & & \\
\hline 33 & 18 & urine & 5 & $(27 \cdot 8)$ & & & \\
\hline 34 & 4 & stool & 2 & (50) & & & \\
\hline 35 & 3 & stool & 2 & $(66 \cdot 7)$ & & & \\
\hline 38 & 6 & urine & 3 & (50) & & & \\
\hline 41 & 4 & sputum & 2 & (50) & & & \\
\hline 49 & 3 & urine & 2 & $(66 \cdot 7)$ & & & \\
\hline 51 & 14 & sputum & 11 & $(78 \cdot 6)$ & & & \\
\hline 54 & 11 & wound & 4 & $(36.4)$ & & & \\
\hline 55 & 10 & urine & 4 & (40) & wound & 3 & (30) \\
\hline 57 & 4 & urine & 2 & (50) & sputum & 2 & (50) \\
\hline 58 & 4 & stool & 2 & (50) & & & \\
\hline 62 & 11 & urine & 5 & $(45 \cdot 5)$ & sputum & 4 & $(36 \cdot 4)$ \\
\hline 65 & 6 & urine & 2 & $(33 \cdot 3)$ & wound & 2 & $(33 \cdot 3)$ \\
\hline 66 & 11 & urine & 5 & $(45 \cdot 5)$ & sputum & 4 & $(36 \cdot 4)$ \\
\hline 69 & 18 & urine & 6 & $(33 \cdot 3)$ & sputum & 8 & $(44 \cdot 4)$ \\
\hline 64 & 14 & sputum & 10 & $(71 \cdot 4)$ & & & \\
\hline
\end{tabular}

Percentages are given in parentheses.

*Cross reaction not separated.

Table 2 Predominant sites of isolation of different klebsiella capsular types. Secondary sites of isolation in parentheses

\begin{tabular}{lccc}
\hline Urine & Sputum & Wound & Stool \\
\hline 2 & 1 & 30 & 14 \\
9 & $(2)$ & 31 & 34 \\
10 or $61^{*}$ & 3 & $(55)$ & 35 \\
11 & 4 & 54 & 58 \\
15 & 12 & 65 & \\
17 & 14 & & \\
18 & $(21)$ & & \\
19 & 23 & & \\
21 & 25 & & \\
24 & $(27)$ & & \\
27 & 41 & & \\
29 & 51 & & \\
$(30)$ & 57 & & \\
33 & $(62)$ & & \\
38 & $(66)$ & & \\
49 & 69 & & \\
55 & 64 & & \\
57 & & & \\
62 & & & \\
65 & & & \\
66 & & & \\
$(69)$ & & & \\
\hline
\end{tabular}

*Cross reaction not separated. however, a small proportion of the total.

Typing of over 1750 unknowns strongly suggested a predilection of some capsular types for certain sites of infection. The first five capsular types are historically associated with the upper respiratory tract, ${ }^{11}$ and indeed types 1,3 , and 4 were isolated primarily from this area while type 2 was recovered secondarily from this site.

In comparison with types related to sites reported in the literature, type $9(75 \%)$ and possibly type 10 were found more frequently in urinary isolates, as was also noted by Kauffmann ${ }^{1}$ and Brooke ${ }^{2}$ even though their isolations may have been due to endemic strains. Henriksen ${ }^{3}$ isolated 26 urinary strains of type 30, while in the Royal Free and Middlesex Hospitals, type 30 occurred primarily in wounds $(43.8 \%)$ and only secondarily in urine $(25 \%)$. Of type 24 isolates $60 \%$ were from urine, which agreed with the view of Steinhauer et al., ${ }^{12}$ who recovered type 24 almost exclusively from urinary tract infections. Type 2 was the most common isolate from urine at the Mayo Clinic, ${ }^{4}$ and in this study more than $50 \%$ of type 2 
strains were from the urine.

Types 8,68 , and 13 were not included in the tables since they were involved in a reported outbreak of infection ${ }^{9}$ and their isolation may have been affected by the epidemic conditions. Nevertheless even during the outbreaks there appeared to be a preference for a particular site, especially a site in which the type could possibly have been more pathogenic. Of type 8 isolates, $40 \%$ were from the skin, and $40 \%$ of type 68 were from the intestinal tract. During a recorded outbreak in a urological war $\mathrm{d}^{8}$ type 21 was recovered mainly from urine specimens. Although these strains were not included in the tables, $39 \%$ of the remaining scattered isolates of this type were still recovered from the urine.

Many types showed a very high percentage of isolation from a particular site, and most of the isolates were well separated by place or time. Useful information could be contributed to this problem by other hospitals making similar studies. Unrelated isolations from different wards and more institutions would provide more significant data; however, known endemic or epidemic strains should also be considered at this stage. It is not yet certain whether endemic or epidemic conditions would cause selection for a particular site or whether such strains would still attack a favoured site preferentially. Our epidemic and single ward observations suggest the latter (except in the case of the urological ward outbreak in which catheters were involved).

Casewell and Talsania ${ }^{13}$ showed a predominance of klebsiella types 21, 2, and 9 in the United Kingdom. They suggested that this may be due to the ability of these types to colonise the bowel or skin, to increased virulence, to multiple-antibiotic resistance, or to some other biological advantage. Type 2 has been responsible for major epidemics in the UK and the United States. Types 21 and 2 were also very common in the Royal Free and Middlesex Hospitals.

Confirming earlier findings, ${ }^{8}$ the present results also indicated no correlation between site of isolation and antibiogram for a given capsular type. The resistance patterns were variable. A type could even express a gain or loss of resistance when taken from the same site in one patient over time. This may have been due to the gain or loss of R-plasmids influenced by antibiotic treatment.

However, it was notable in the light of Casewell and Talsania's work that types $2,9,10,19$, and 21 were more resistant in urine than in other specimens. Types 2 and 21 were also very resistant in sputum. This resistance paralleled the most frequent sites of isolation for these types. Type 8 isolates also showed greater resistance when recovered from the skin where this type was more predominant. More multiple-resistance in isolates from the urinary tract occurred among types $2,9,10,16,19,21,26,29$, and 32 . Blood culture strains were almost invariably multiply of resistant.

However, type 13 was less resistant in its most common sites of the skin and rectum than in the $\frac{\bar{\omega}}{\frac{5}{\sigma}}$ urine or throat. Type 14 also showed greater resist $-\stackrel{\mathbb{Q}}{\Omega}$ ance in urine than in the more frequent stool and sputum isolates, and type 68 was not more resistant $\vec{\circ}$ when recovered from the rectum than from less: common sites.

Greater resistance of a type in less common sites $\stackrel{\mathscr{\omega}}{\stackrel{5}{\circ}}$ (usually urine) could be due to treatment and implies? that a factor other than the ability to accumulate $\omega_{+}$ R-plasmids is necessary for infection. Again, their specificity of a type for a site appears to be significant. $\mathrm{G}$ And when this is combined with resistance and probably another 'virulence factor' (since not all $\stackrel{5}{-}$ types appear to have a predominant site and, when $\vec{z}$ they do, may not be important disease producers) then the organism could become a very pathogenic $\vec{P}$ strain.

Correlation of type with disease does seem to be $\mathrm{e}^{-}$ significant. A difference in virulence related to serotype has been noted. Pierog et al. ${ }^{14}$ reported an epidemic of neonatal septicaemia of unusually lowo virulence due to $K$. pneumoniae type 60 . Virulence studies in mice showed that a $K$. pneumoniae type $33 \stackrel{\circ}{\circ}$ isolated from blood and tracheal aspirates was $\overrightarrow{0}$ considerably more virulent than klebsiella types 11,3 19 , and 30 from the same sites in other patients. ${ }^{15}$ Some types may in fact be more virulent than others? or they may prove to be commensals in one site and pathogens in another. ${ }^{9}$ Conditions in different sites:might favour different organisms. Reinarz ${ }^{16}$ reports 3 . that, for an organism to invade tissue, it must firstio be present at a susceptible site, become attached, and 3 begin to multiply. Attachment sites on mucouso membranes appear to be specific for particular? organisms, and this specificity may be involved in virulence.

Bacteria attach with a high degree of specificity and different bacteria adhere to different surfaces. ${ }^{1}$ in There can be a variation in adsorption by strains inN the same genus, and bacteria can lose the ability to adsorb on culturing.

Our data suggest that some serotypes of klebsiell角 are selective for the sites they colonise and may also $2 ?$ show differences in virulence in different sites. Sucho information may be useful in assessing the signifio cance of Klebsiella species isolated from clinica $\vec{B}$ specimens, especially in immunologically com $\vec{Q}$ promised, hospitalised patients in high-risk units undergoing regular microbial 'surveillance' investi gations. 


\section{References}

${ }^{1}$ Kauffmann F. On the serology of the klebsiella group. Acta Pathol Microbiol Scand 1949;26:381-406.

2 Brooke MS. Further capsular antigens of klebsiella strains. Acta Pathol Microbiol Scand 1951;28:313-27.

${ }^{3}$ Henriksen SD. Studies on the klebsiella group (Kauffmann). 1. Serotypes of a collection of strains from human sources and from water. Acta Pathol Microbiol Scand 1954;34:249-58.

4 Martin WJ, Yu PKW, Washington JA. Epidemiologic significance of Klebsiella pneumoniae. A 3-month study. Mayo Clin Proc 1971;46:785-93.

${ }^{5} \emptyset$ rskov I. Noscomial infections with klebsiella in lesions of the urinary tract. Acta Pathol Microbiol Scand 1952;93, suppl:259-71.

- Casewell M. The epidemiology of Klebsiella species in an intensive care unit. MD thesis, 1978. London University.

${ }^{7}$ Ørskov I. Serological investigations in the klebsiella group. 2. Occurrence of klebsiella in sputa. Acta Pathol Microbiol Scand 1955;36:454-60.

${ }^{8}$ Riser E, Noone P, Thompson REM. The use of a fluorescence typing method in an epidemiological study of Klebsiella infection in a London hospital. J Hyg (Camb) 1978;80:43-56.

- Riser E, Noone P, Howard F. Epidemiological study of klebsiella infection in the special care baby unit of a London hospital. J Clin Pathol 1980;33:400-7.

${ }^{10}$ Riser E, Noone P, Poulton TA. A new serotyping method for Klebsiella species: development of the technique. $J$ Clin Pathol 1976;29:296-304.

${ }^{11}$ Weiss W, Eisenberg GM, Spivack A, Nadel J, Kayser HL, Sathavara S, Flippin HF. Klebsiella in respiratory disease. Ann Intern Med 1956;45:1010-26.

12 Steinhauer BW, Eickhoff TC, Kislak JW, Finland M. The Klebsiella-Enterobaster-Serratia division. Clinical and epidemiologic characteristics. Ann Intern Med 1966;65: 1180-94

${ }^{13}$ Casewell M, Talsania HG. Predominance of certain klebsiella capsular types in hospitals in the United Kingdom. J Inf 1979;1:77-9.

${ }^{14}$ Pierog S, Nigam S, Lala RV, Crichlow DK, Evans HE. Neonatal septicemia due to Klebsiella pneumoniae type 60. Epidemic of unusually low virulence. $N Y$ State $J$ Med 1977;77:737-41.

15 Hable KA, Matsen JM, Wheeler DJ, Hunt CE, Quie PG. Klebsiella type 33 septicemia in an infant intensive care unit. Pediatr 1972;80:920-4.

16 Reinarz JA. Nosocomial infections. Clin Symp 1978;30: 1-32.

17 Gibbons RJ. Adherence of bacteria to host tissue: position paper. In: Schlessinger D, ed. Microbiology-1977. Washington, DC: American Society of Microbiology, 1977:395-406.

Requests for reprints to: Dr P Noone, The Royal Free Hospital, Pond Street, Hampstead, London NW3 2QG, England. 